\title{
Avaliação do impacto da implantação do sistema de esgotamento sanitário na qualidade da água da Bacia Hidrográfica do Rio Cachoeira, em Joinville, Santa Catarina.
}

\section{Evaluation of the impact of the implantation of the sewage system on the water quality of the Cachoeira River Basin, in Joinville, Santa Catarina.}

\section{Resumo}

A compreensão das relações entre saneamento, saúde pública e meio ambienteéessencial para o planejamento dos sistemas de saneamento nas cidades. Desta forma, o objetivo deste trabalho foi realizar uma avaliação do impacto da implantação do sistema público de esgotamento sanitário na qualidade da água da Bacia Hidrográfica do Rio Cachoeira, em Joinville, que abrange quase metade da população da cidade. Foram realizadas análises da qualidade da água em 10 pontos ao longo dos anos de 2011 a 2015, período em que foram incrementadas mais de 31.000 economias de esgoto nas sub-bacias do rio. Para cálculo da qualidade da água, utilizou-se o IQQA - Índice de Qualidade da Água, padrão Cetesb. De forma geral, o IQA médio do rio evoluiu de ruim para regular, fruto de uma redução estimada no lançamento de esgoto de mais de cinco milhões de litros ao dia.

Palavras-chave: Rio Cachoeira. Poluição. IQQA. Qualidade.

\section{Abstract}

Understanding the relationships between sanitation, public health and the environment is essential for planning sanitation systems in cities. Thus, the objective of this study was to evaluate the impact of the implantation of the public sewage system on the water quality of the Cachoeira River Basin in Joinville, which covers almost half of the population of the city. Waterquality analyzes were carried out in 10 points overtheyears 2011 to 2015, during which time more than 31,000 sewage economies were increased in the Cachoeira River sub-basins. In order to calculate the waterquality, was used the WQI-WaterQuality Index, Cetesbstandard. In general, the averageIQA of the riverhas developed from bad to regular, due to a reduction in the discharge of sewage of more than five million liters per day.

Keywords: Cachoeira River. Pollution. WQI. Quality.

\footnotetext{
Thiago Zschornack - Mestrado em Saúde e Meio Ambiente. Especialista em Engenharia de Produção, Suprimentos e Segurança do Trabalho, MBA em Gestão Ambiental e MBA em Gestão de Projetos. Graduado em Administração, Sistemas de Informação e Ciências Contábeis. Graduando em Engenharia de Produção. Professor universitário e analista na Companhia Águas de Joinville.

Therezinha Maria Novais de Oliveira - Pós-doutorado em Engenharia Sanitária. Mestrado e Doutorado em Engenharia de Produção. Graduação em Engenharia Sanitária. Professora titular e coordenadora do Programa de Pós-Graduação em Saúde e Meio Ambiente da Univille.

"Endereço para correspondência: Universidade da Região de Joinville, Programa de Pós-Graduação em Saúde e Meio Ambiente. Rua Paulo Malschitzki N-10. Zona Industrial Norte. 89.219710 - Joinville, SC.
} 


\section{INTRODUÇÃO}

No Brasil, informações do SNIS-Sistema Nacional de Informações sobre Saneamento (2014) indicam elevados índices de internações hospitalares por diarreia, uma doença claramente relacionada ao inadequado saneamento ambiental. Diversas doenças infecciosas e parasitárias têm no meio ambiente uma fase de seu ciclo de transmissão, como por exemplo, as de veiculação hídrica, com transmissão feco-oral.

Um dos mecanismos de combate à poluição dos cursos d'água é a implantação de ações de saneamento básico, com a correta gestão dos resíduos sólidos, da drenagem urbana, do abastecimento de água e, principalmente, do sistema de coleta e tratamento de esgoto, proporcionando, assim, a eliminação de condições deletérias à saúde (IBGE, 2008).

O município de Joinville, situado na região nordeste do Estado de Santa Catarina, é considerado o terceiro polo industrial da Região Sul do Brasil. Segundo dados da Fundação Instituto de Pesquisa e Planejamento Urbano de Joinville (IPPUJ, 2015), o produto interno bruto per capita de Joinville figura entre os 15 maiores do país. Da mesma forma que outras regiões, Joinville possui um dos seus principais rios bastante poluído, seja por efluentes domésticos e industriais ou por resíduos sólidos. Pelos dados divulgados pelo SNIS em 2015, base 2014, nos quais se consideravam as cidades com mais de 100 mil habitantes, Joinville aparecia entre as 10 piores do Brasil em cobertura de esgoto, com um pouco mais de $18 \%$ de cobertura.

A Bacia do Rio Cachoeira, alvo de estudo deste trabalho, está inserida na região central da cidade de Joinville. Sua nascente localiza-se no bairro Costa e Silva, a 40 metros de altura do nível do mar, e sua foz é caracterizada por estuário sob influência de marés e onde se encontram áreas com remanescentes de manguezais.

No início do século XX, o Rio Cachoeira, principal rio dessa bacia, ainda possuía águas limpas e era possível tirar dele várias espécies de peixes. No entanto, com o rápido aumento da população na década de 70 , motivado pela imigração em função do "boom" industrial, houve um aumento significativo na quantidade de resíduos domésticos lançados no rio.

Infelizmente, os primeiros investimentos em esgotamento sanitário na cidade ocorreram apenas no final da década de 80. Ainda assim, pararam por ali. Do final da década de 80 até a metade dos anos 2000, não houve mais nenhum incremento de coleta e tratamento de esgoto na cidade. A cidade ficou quase três décadas com pífios $14 \%$ de cobertura.

Despoluir o Rio Cachoeira tem sido um desejo antigo da população joinvilense, por isso, quase sempre, esteve presente em planos de governo das várias gestões da cidade, embora nenhuma iniciativa tenha trazido resultados concretos. A partir de 2005, essa situação começou a mudar. De 2005 até 2015, foram realizados em Joinville diversos investimentos na expansão do sistema de esgotamento sanitário. A maior parte das obras se concentrou justamente na Bacia Hidrográfica do Rio Cachoeira, que abrange quase metade da população do município.

A importância deste estudo consiste no pressuposto de que, identificando a melhoria da qualidade da água do Rio Cachoeira após as obras de ampliação da cobertura de esgoto, podem-se inferir alguns benefícios, tais como: a melhoria da condição ambiental do rio e de seu ecossistema, a melhoria na condição sanitária no município, com impactos diretos na saúde e no bem-estar social das pessoas que residem nessa bacia e nos respectivos gastos públicos destinados para este fim e, acima de tudo, uma rica base de informações para subsídio em pleitos para novos investimentos em coleta e tratamento de esgoto na cidade, fato que possibilitará a universalização do acesso ao sistema de esgotamento sanitário. 


\section{METODOLOGIA}

Este trabalho segue uma abordagem qualitativo-quantitativa. Segundo Cherobim et al (2003), quando a realidade pesquisada permite evidências qualitativas e quantitativas, o principal argumento para desenvolver uma pesquisa a partir da abordagem combinada é consubstanciar a análise, explorando ao máximo a realidade pesquisada e extraindo a maior quantidade possível de informações do banco de dados obtido.

No caso em questão, utilizou-se majoritariamente a abordagem quantitativa, intercalada com alguns recursos da abordagem qualitativa.

A abordagem quantitativa foi utilizada para análise estatística dos dados de qualidade da água, incremento de ligações de esgoto e fiscalização de ligações, todos obtidos do Laboratório de Controle de Qualidade da Companhia Águas de Joinville, concessionária dos serviços de água e esgoto na cidade de Joinville.
Visando a uma análise e interpretação mais aprofundadas do comportamento do IQA - Índice de Qualidade de Água, foram realizadas conversas com os técnicos de vários setores da Companhia Águas de Joinville - CAJ, da Secretaria de Meio Ambiente do município e do Comitê de Gerenciamento das Bacias Hidrográficas dos Rios Cubatão e Cachoeira. O objetivo dessas conversas foi buscar evidências que permitissem fundamentar os resultados obtidos.

\section{1 Área de estudo}

A Bacia Hidrográfica do Rio Cachoeira faz parte do complexo Hídrico da Baia Babitonga, estando totalmente inserida na área urbana de Joinville, conforme se visualiza na figura 1. Drena uma área de $83,12 \mathrm{~km}^{2}$, que representa $7,3 \%$ da área do município ao longo de seu curso, de 14,9 km de extensão. Aproximadamente $49 \%$ da população reside dentro do perímetro da bacia que é de 59,31 km.

Figura 1 - Localização da Bacia Hidrográfica do Rio Cachoeira

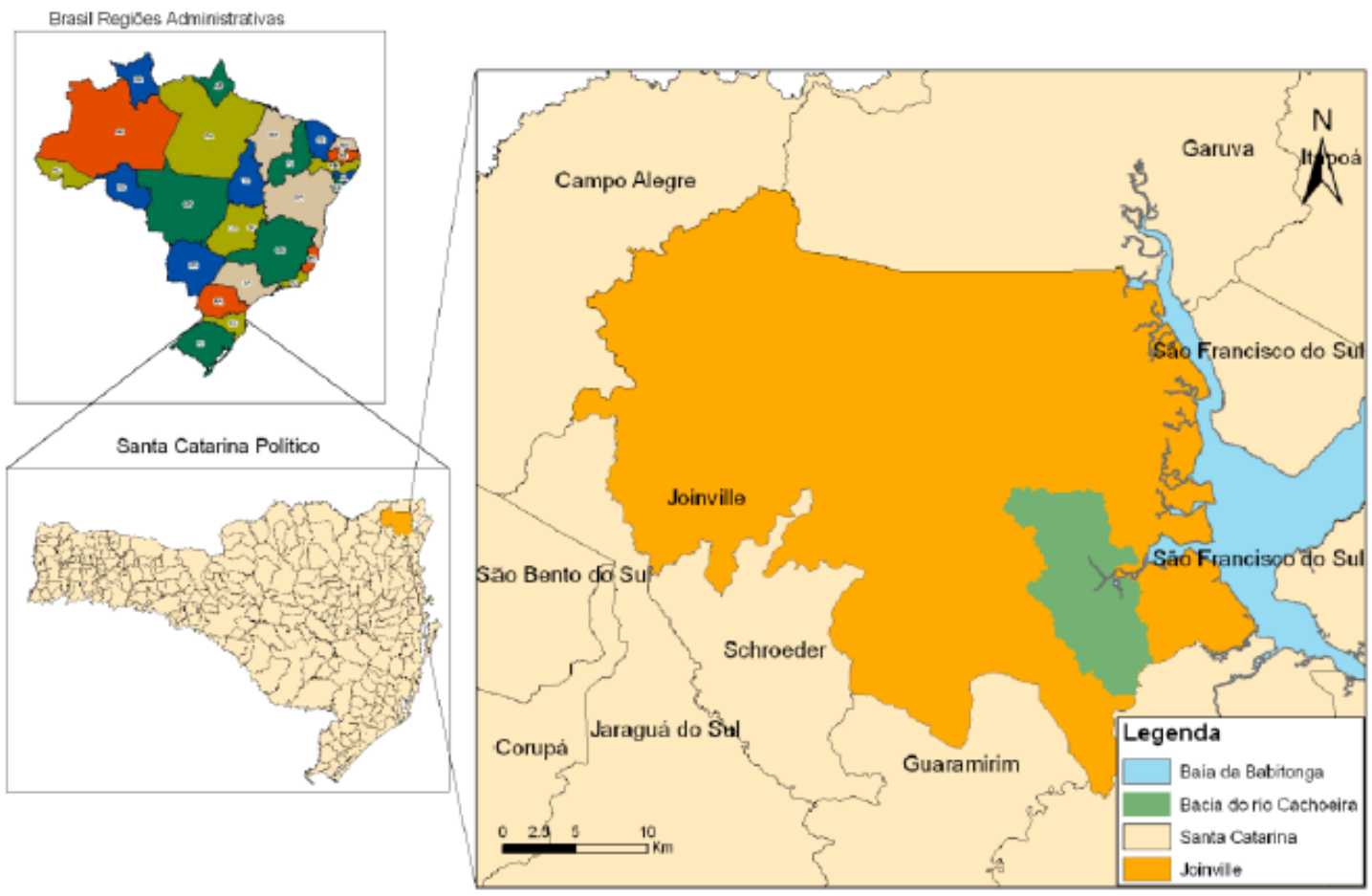

Fonte: Centro de Cartografia Digital - Univille (2011) 
Como a Bacia Hidrográfica do Rio Cachoeira ainda não possui plano diretor de recursos hídricos, adota-se a classificação estabelecida pela Resolução nº 357/2005 do Conselho Nacional de Meio Ambiente - Conama, que em seu art. 42 estabelece que "enquanto não aprovados os respectivos enquadramentos, as águas doces serão consideradas classe 2".

Na figura 2, apresenta-se a subdivisão das bacias do Rio Cachoeira em "sub-bacias de esgoto". Essa divisão e numeração é uma prática adotada pela Companhia Águas de Joinville para auxiliar no planejamento das obras de expansão do município.

Figura 2 - Distribuição das bacias de esgoto na Bacia Hidrográfica do Rio Cachoeira

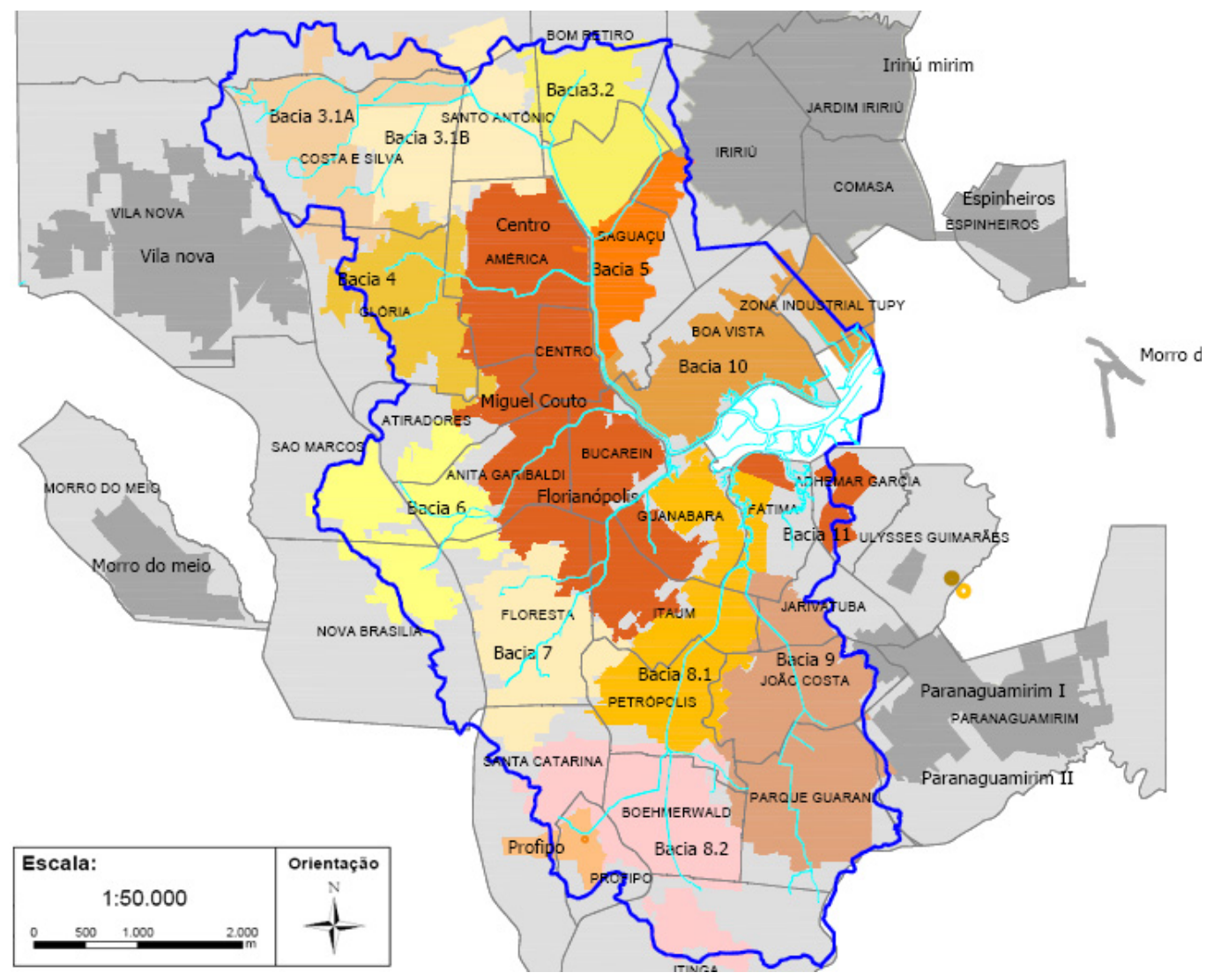

Fonte: Arquivo interno da CAJ - Plano de Expansão de Esgoto (2015)

\subsection{Rio Cachoeira}

O rio Cachoeira é o principal rio da Bacia Hidrográfica do rio Cachoeira. Sua nascente fica no bairro Costa e Silva, no Morro da Tromba, na junção das ruas Rui Barbosa e Estrada dos Suíços, logo após a Rodovia Federal BR-101. Ao longo de seus quase catorze quilômetros de extensão, recebe diversos afluentes, entre eles os rios Morro Alto, Mathias, Jaquarão; Bucarein, Bom Retiro e o Boa Vista. O Rio Cachoeira e seus afluentes pertencem exclusivamente a Joinville, ocupando uma área de cerca de noventa e dois quilômetros quadrados, o que envolve nove bairros da cidade. 
Desde a chegada dos primeiros colonizadores até hoje, seu leito sofreu uma série de interferências, sempre visando evitar enchentes ou para adaptá-lo a navegação.

Como o rio deságua na Lagoa do Saguaçú, que liga à Baía da Babitonga, a foz é caracterizada por estuário sob a influência de marés. Assim, numa maré alta, na lua cheia, há uma inversão do fluxo de água em mais da metade de seu percurso, causando entrada de água salgada (MAIA et al, 2014).

\subsection{Pontos de coleta das amostras de água}

Os pontos de coletas foram definidos pela Companhia Águas de Joinville. A escolha dos pontos levou em consideração os seguintes critérios: cronograma-físico de ativação das ligações de esgoto da empresa (para comparação do antes e depois da implantação do esgoto) e acessibilidade para a coleta.

Os pontos de coleta, as bacias e sub-bacias abrangidas, as bacias à montante e a data de liberação das ligações das bacias à montante seguem apresentadas na tabela 1 e na figura 3 .

Tabela 1 - Pontos de coleta e sub-bacias de abrangência

\begin{tabular}{|c|c|c|c|c|}
\hline Ponto de coleta & Bacia abrangida & $\begin{array}{l}\text { Sub-bacia } \\
\text { abrangida }\end{array}$ & $\begin{array}{l}\text { Bacia(s) a } \\
\text { montante }\end{array}$ & $\begin{array}{l}\text { Liberação } \\
\text { conexão }\end{array}$ \\
\hline $\begin{array}{l}\text { RBC1 - Rio Jaguarão, } \\
\text { Pontilhão na Rua Urussanga } \\
\text { (Fundos Havan); }\end{array}$ & Bacia Centro (Casan) & Centro/ Bucarein & Bacia 6 & $01 / 01 / 1980$ \\
\hline $\begin{array}{l}\text { RBC3 - Rio Morro Alto, } \\
\text { Pontilhão na Rua Orestes } \\
\text { Guimarães (Centreventos); }\end{array}$ & Bacia Centro (Casan) & América / Atiradores & Bacia 4 & $01 / 01 / 1980$ \\
\hline $\begin{array}{l}\text { RBC4 - Rio Mirandinha, } \\
\text { Pontilhão Rua Dona Francisca; }\end{array}$ & Bacia 5 & A & Bacia 3.2 & $31 / 01 / 2012$ \\
\hline $\begin{array}{l}\text { RBC5 - Rio Mirandinha, } \\
\text { Pontilhão Rua Rio Negrinho; }\end{array}$ & Bacia 5 & A & Bacia 3.2 & $31 / 01 / 2012$ \\
\hline $\begin{array}{l}\text { RBC6-Rio Mirandinha, } \\
\text { Pontilhão Rua da Américas; }\end{array}$ & 3.2 & $1(\mathrm{C})$ & - & $22 / 09 / 2014$ \\
\hline $\begin{array}{l}\text { RBC7 - Rio Cachoeira, } \\
\text { Pontilhão na Rua Prudente de } \\
\text { Moraes (Flotflux); }\end{array}$ & $3.1 \mathrm{~B}$ & 27 & Bacia 3.1A & $21 / 09 / 2012$ \\
\hline $\begin{array}{l}\text { RBC8 - Rio Bom Retiro, } \\
\text { Pontilhão na Rua Gen. } \\
\text { Camara; }\end{array}$ & 3.2 & $2(\mathrm{G})$ & - & $22 / 09 / 2014$ \\
\hline $\begin{array}{l}\text { RBC9 - Rio Cachoeira/Alvino } \\
\text { Vohl, Pontilhão na Rua João } \\
\text { Vogelsanger; }\end{array}$ & 3.1B & 20 & - & $17 / 03 / 2016$ \\
\hline $\begin{array}{l}\text { RBC10 - Rio Cachoeira, } \\
\text { Pontilhão na Rua Felix } \\
\text { Heinzelmann; }\end{array}$ & $3.1 \mathrm{~B}$ & 11 & Bacia 3.1A & $20 / 02 / 2014$ \\
\hline $\begin{array}{l}\text { RBC11 - Rio Cachoeira, } \\
\text { Pontilhão na Rua Alicia } \\
\text { Bittencourt Ferreira. }\end{array}$ & $3.1 \mathrm{~A}$ & 32 & - & $26 / 09 / 2014$ \\
\hline
\end{tabular}

Fonte: $\mathrm{O}$ autor (2016) 
Figura 3 - Pontos de coleta e sub-bacias de abrangência

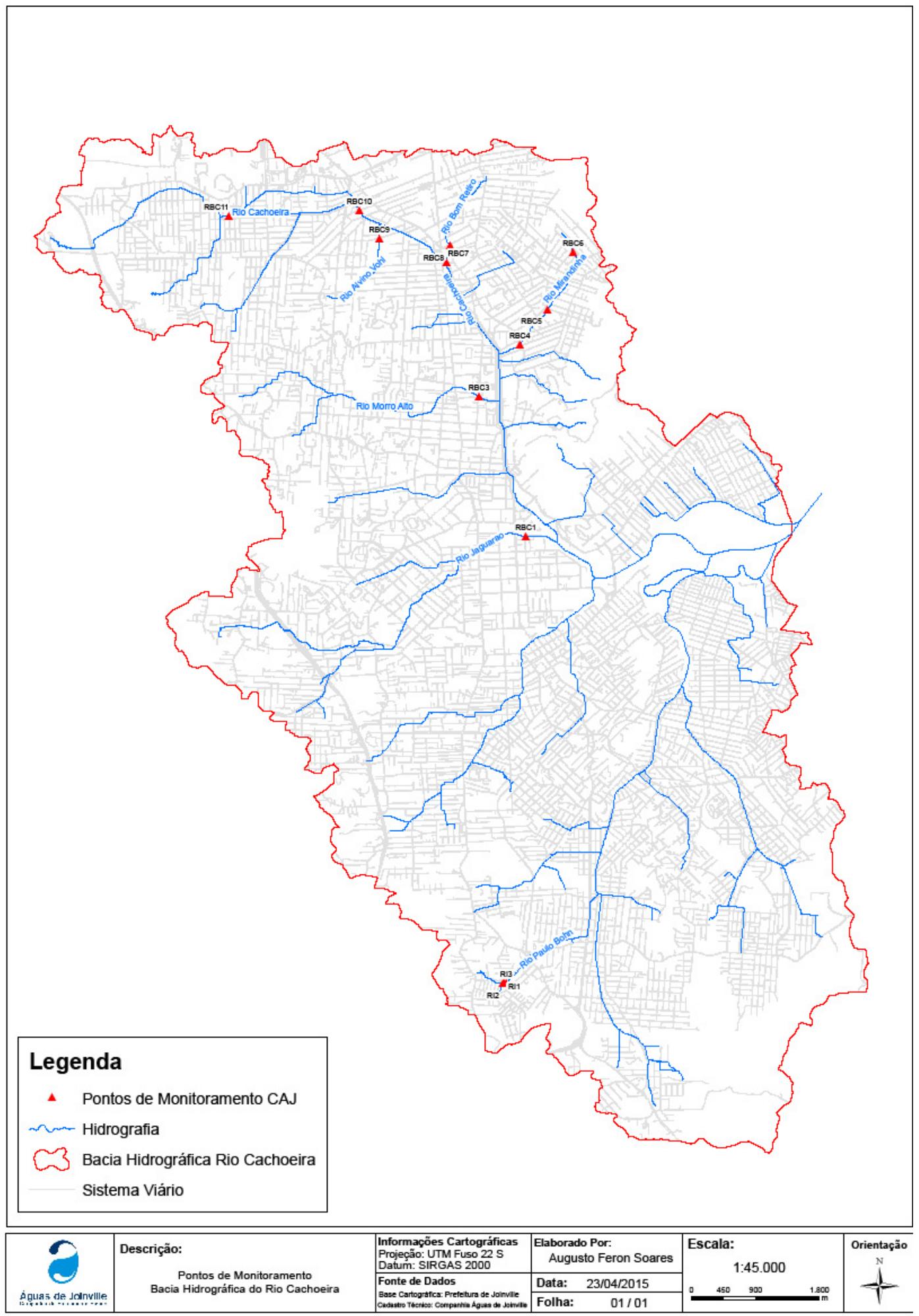

Fonte: Arquivo interno da CAJ (2015) 


\section{4 Índice de Qualidade da Água - IQA}

$O$ índice escolhido para medição da qualidade da água foi o IQA - Índice de Qualidade da Água. Este índice foi adaptado pela Cetesb - Companhia Ambiental do Estado de São Paulo a partir do NSF-WQ̣I da National Sanitation Foundation - NSF. A NSF, com sede nos EUA, desenvolveu esse indicador na década 70. O trabalho contou com a participação de diversos pesquisadores e tinha como objetivo principal criar um indicador padrão para medição e comparação da qualidade da água entre os vários países.

Segundo Piasentin et al (2009), esse índice foi desenvolvido visando avaliar o impacto dos esgotos domésticos nas águas utilizadas para abastecimento público, não representando efeitos originários de outras fontes poluentes.

O IQA traz dados de qualidade de água inter-relacionados, aglutinando as variáveis em um indicador único (DERÍSIO, 2000).

Ele é definido pelo produto ponderado das qualidades de água correspondentes aos parâmetros: temperatura da amostra, $\mathrm{pH}$, oxigênio dissolvido, demanda bioquímica de oxigênio ( 5 dias, $20^{\circ} \mathrm{C}$ ), coliformes termotolerantes, nitrogênio total, fósforo total, resíduo total e turbidez, conforme apresentado no Quadro 10.

Tabela 2 - Parâmetros e pesos utilizados no IQA

\begin{tabular}{|c|c|c|}
\hline Variáveis & Unidades & Peso (W) \\
\hline Coliformes fecais & NMP/ $100 \mathrm{~mL}$ & 0,15 \\
\hline $\mathrm{pH}$ & - & 0,12 \\
\hline DBO5 & $\mathrm{mg} / \mathrm{L}$ & 0,10 \\
\hline Nitrogênio Total & $\mathrm{mg} / \mathrm{L}$ & 0,10 \\
\hline Fósforo Total & $\mathrm{mg} / \mathrm{L}$ & 0,10 \\
\hline Temperatura & ${ }^{\circ} \mathrm{C}$ & 0,10 \\
\hline Turbidez & UNT & 0,08 \\
\hline Sólidos Totais & $\mathrm{mg} / \mathrm{L}$ & 0,08 \\
\hline Oxigênio Dissolvido & $\%$ saturação & 0,17 \\
\hline
\end{tabular}

A equação utilizada para cálculo do IQA segue apresentada na equação 1:
Equação 1 - Fórmula de cálculo do IQQA

$\mathrm{IQA}=\prod_{i=1}^{\mathrm{n}} \mathrm{q}_{\mathrm{i}}{ }^{{ }{ }{ }_{i}}$

Fonte: Cetesb (2011)

Onde:

IQA = Índice de Qualidade de Água, representado por um número em escala contínua de 0 a 100.

$\mathrm{q}_{\mathrm{i}}=$ qualidade individual (sub-índice de qualidade) do i-ésimo parâmetro, um valor de 0 a100.

$\mathrm{w}_{\mathrm{i}}=$ é o peso atribuído ao parâmetro $\mathrm{i}$.

$\mathrm{i}$ = número de parâmetros

Além de seu peso (w), cada parâmetro possui um valor de qualidade (q), obtido do respectivo gráfico de qualidade em função de sua concentração ou medida. Esse gráfico pode ser obtido no site da Cetesb ou da ANA - Agência Nacional de Águas.

Depois de realizados os cálculos, o IQA classifica a água de acordo com o valor atribuído à mesma, conforme se verifica na figura 4 .

Figura 04 - Faixas de classificação do IQAA

\begin{tabular}{|c|c|}
\hline Valor & Qualificação \\
\hline $80-100$ & Ótima \\
\hline $52-79$ & Boa \\
\hline $37-51$ & Razoável \\
\hline $20-36$ & Ruim \\
\hline $0-19$ & Péssima \\
\hline \multicolumn{2}{|c|}{ Fonte: Cetesb (2011) } \\
\hline
\end{tabular}

\subsection{Coleta de dados}

Os dados de qualidade da água do Rio Cachoeira foram coletados do banco de dados da Companhia Águas de Joinville e compreenderam o período de 2011 a 2015.

Os dados da variação da maré foram obtidos do site da Defesa Civil de Joinville. Esses valores refe- 
rem-se à maré astronômica e são calculados pela Marinha do Brasil.

Os dados de precipitação pluviométrica foram coletados do site do Comitê de Gerenciamento das Bacias Hidrográficas do Rio Cubatão e Rio Cachoeira - CCJ, e a fonte dos mesmos é a Estação Meteorológica da Universidade da Região de Joinville.

Os dados de vazão foram obtidos do Comitê de Gerenciamento das Bacias Hidrográficas do Rio Cubatão e Rio Cachoeira - CC), e referem-se ao ponto CA1, localizado no Bairro América, no encontro das ruas João Pessoa e Marcos Welmut, cujas medições são realizadas mensalmente desde 2010. Esse ponto fica localizado entre os pontos RBC1 e RBC3.

Os dados das ligações de esgoto foram coletados do banco de dados da Companhia Águas de Joinville e referem-se ao período de 2011 a 2015. Os dados sobre as fiscalizações das ligações domiciliares de esgoto também foram coletados do banco de dados da empresa e referem-se ao período de 2015, ano em que a concessionária iniciou a fiscalização na Bacia Hidrográfica do Rio Cachoeira. A concessionária apenas considera ativas as ligações de esgoto que foram liberadas para a conexão há mais de 90 dias.

\subsection{Análise dos Resultados}

Para efeito das análises deste trabalho, em especial da evolução do IQA e dos nove parâmetros que o compõem, foi utilizada a estatística descritiva: média, desvio-padrão e coeficiente de variação, bem como foi feita a comparação do resultado de cada parâmetro com os padrões estabelecidos na Resolução Conama 357/2005. O coeficiente de variação foi utilizado para possibilitar a comparação entre parâmetros com unidades de medida diferentes.

Para apuração dos valores do IQA foi utilizado o programa gratuito QualiGraf - versão 2014, dispo- nivel para download no site da Funceme - Fundação Cearense de Meteorologia e Recursos Hídricos.

Adicionalmente foi utilizada análise de correlação (Pearson e Spearman) para medir a correlação entre:

a) Altura da maré e o IQQA obtido

b) Altura da maré e os parâmetros: DBO, OD e Coliformes Termotolerantes.

Em estatística descritiva, o coeficiente de correlação de Pearson mede o grau da correlação (e a direção dessa correlação; se positiva ou negativa) entre duas variáveis de escala métrica (intervalar ou de razão). Interpretando:

- 0,9 para mais ou para menos indica uma correlação muito forte.

- 0,7 a 0,9 positivo ou negativo indica uma correlação forte.

- 0,5 a 0,7 positivo ou negativo indica uma correlação moderada.

- 0,3 a 0,5 positivo ou negativo indica uma correlação fraca.

- 0 a 0,3 positivo ou negativo indica uma correlação desprezível.

Contudo, a utilização do coeficiente de correlação de Pearson pode ser questionada, uma vez que a maioria dos parâmetros não segue uma distribuição normal e que em vários casos existe a presença de valores extremos. Em função de a maioria dos dados não possuir uma distribuição normal, foi utilizado adicionalmente a Correlação de Spearman, que em vez de trabalhar com os valores originais das variáveis, trabalha com seus postos (número de ordem daquele valor), eliminando a influência dos valores extremos. 


\section{RESULTADOS E DISCUSSÃO}

\subsection{Ativação das ligações de esgoto}

Na tabela 3 é apresentada a distribuição das economias ativadas na Bacia Hidrográfica do Rio Cachoeira no período de 2011 a 2015.

Tabela 3 - Economias ativadas na Bacia do Rio Cachoeira (2011-2015)

\begin{tabular}{|c|c|c|c|c|c|c|c|}
\hline Regiões & Economias Existentes & 2011 & 2012 & 2013 & 2014 & 2015 & Total \\
\hline Bacia 3.1A & - & 0 & 0 & 0 & 1.920 & 3.811 & 5.731 \\
\hline Bacia 3.1B & - & 0 & 875 & 2.167 & 3.472 & 1.398 & 7.912 \\
\hline Bacia 3.2 & - & 0 & 0 & 0 & 390 & 6.110 & 6.500 \\
\hline Bacia 4 & - & 0 & 850 & 547 & 1388 & 1189 & 3.974 \\
\hline Bacia 5 & - & 2.535 & 473 & 41 & 196 & -40 & 3.205 \\
\hline Bacia 6 & - & 0 & 0 & 0 & 1702 & 85 & 1.787 \\
\hline Centro & 24.607 & $332 *$ & 1933* & $-313^{*}$ & $958 *$ & $-936^{* * * * * * *}$ & 26.581 \\
\hline Fátima & 841 & $10 *$ & $32 *$ & $-94^{*}$ & $-3^{*}$ & $36 *$ & 822 \\
\hline $\begin{array}{c}\text { Ulisses } \\
\text { Guimarães }\end{array}$ & - & 0 & 0 & 0 & 0 & 581 & 581 \\
\hline Adhemar Garcia & 420 & $3 *$ & $4 *$ & $5 \%$ & $1 *$ & $1 *$ & 434 \\
\hline Profipo*** & 539 & 0 & 0 & 200 & 0 & 0 & 739 \\
\hline Total & 26.407 & 2.880 & 4.167 & 2.553 & 10.024 & 12.235 & 58.266 \\
\hline
\end{tabular}

Fonte: O autor (2016)

* Refere-se exclusivamente ao crescimento vegetativo ou a pequenas extensões de rede.

*:* Refere-se a economias ativas, porém não faturadas devido a problemas de acesso às redes.

***: Reflexo da alteração na resolução 52/2015 da AMAE - Agência Reguladora Municipal de Joinville no que diz respeito à categoria comercial.

Os resultados apresentados nas Figuras 5 e 6 mostram a situação das ligações domiciliares nas Bacias de Esgotamento Sanitário 3.1A e 3.1B, no período compreendido entre julho de 2015 e março de 2016.

Figura 5 - Situação das ligações domiciliares

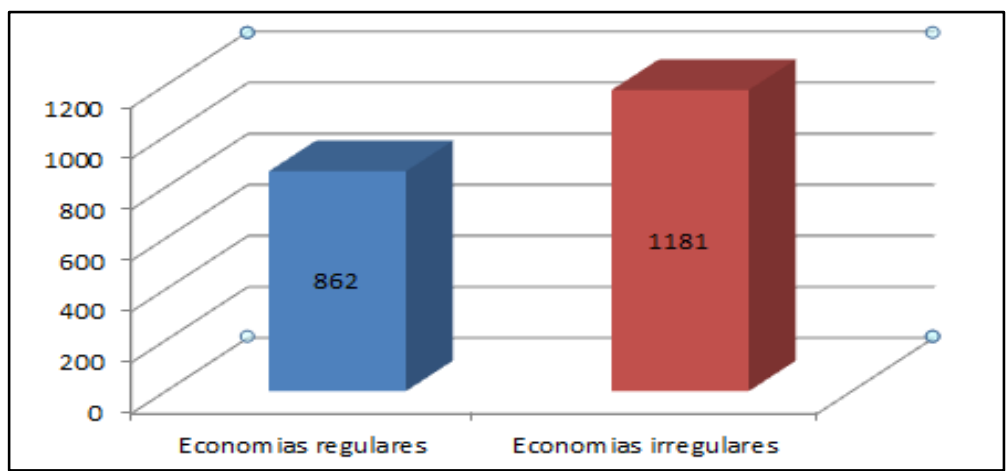

Fonte: Arquivo interno da CAJ (2016) 
Figura 6 - Tipo de irregularidade das ligações

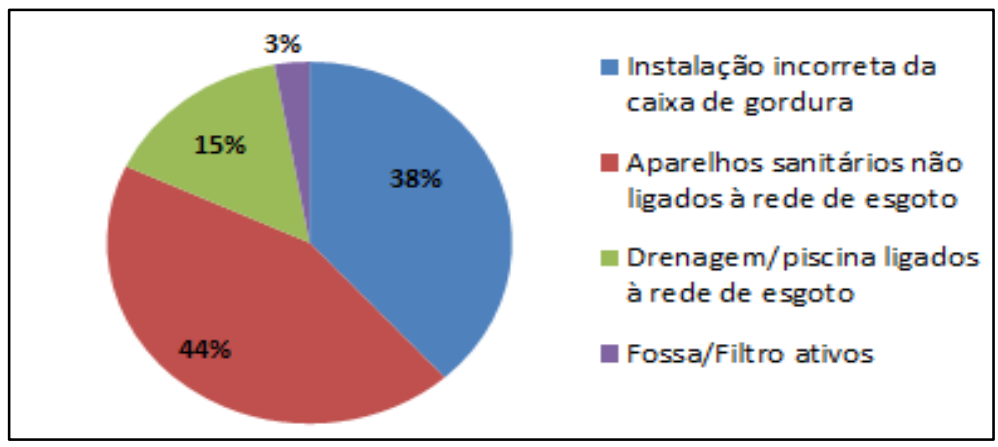

Fonte: Arquivo interno da CAJ (2016)

Os resultados encontrados mostram um percentual significativo de ligações irregulares na rede coletora de esgoto - quase $60 \%$. No tocante aos tipos de irregularidades, verifica-se que o de maior ocorrência é o de "aparelhos sanitários não ligados à rede de esgoto" $-44 \%$ do total.

\subsection{Análise da Qualidade da Água}

Considerando a média aritmética dos Índices de Qualidade de Água dos 10 pontos avaliados neste estudo, apresenta-se na figura 7 a evolução do IQA Geral de 2011 a 2015. Se consideradas apenas as médias dos anos 2011 e 2015, o IQA Geral evoluiu de 27,5 para 45,8 .

Figura 7 - IQQA Geral

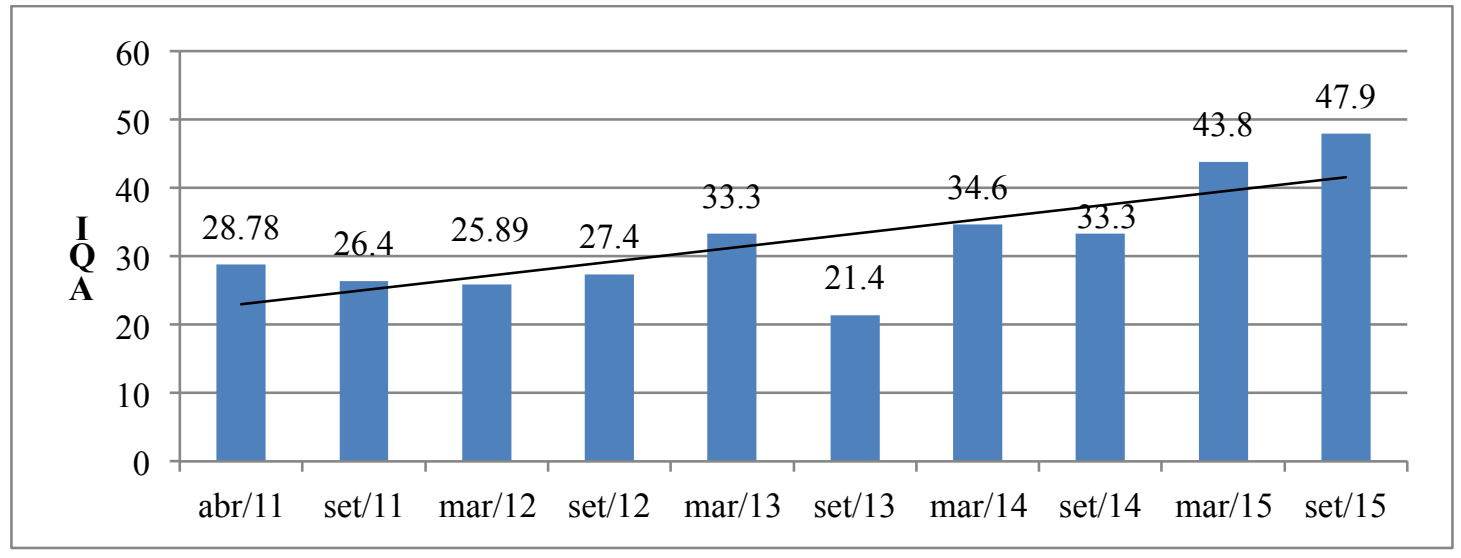

Fonte: O autor (2016)

Se a apresentação dos dados for feita considerando os 10 pontos em um único gráfico, conforme apresentado na figura 8, é possível observar que a evolução do IQQA tem ocorrido em todos os pontos, de forma bastante distribuída. 
Figura 8 - IQA por ponto monitorado

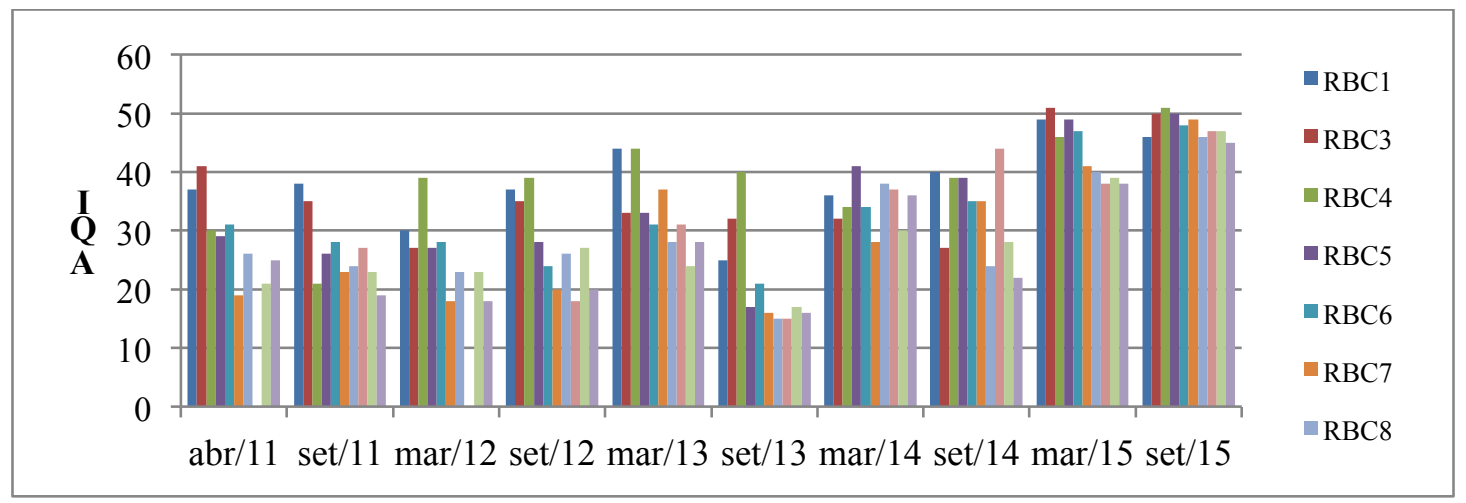

Fonte: O autor (2016)

\subsubsection{Análise por ponto e parâmetro}

Analisando a variação dos nove parâmetros considerados ao longo do período de 2011 a 2015, percebeu-se que, desconsiderando os parâmetros de pH e temperatura, que não apresentaram variação significativa e sempre atenderam aos limites estabelecidos pela Resolução Conama 357/2005, todos os demais parâmetros apresentaram uma melhora considerável. $O$ destaque maior ficou por conta dos parâmetros com maior peso na composição do IQQA, que são: OD - Oxigênio Dissolvido, DBO - Demanda Bioquímica de Oxigênio e CT - Coliformes Termotolerantes. Avaliando esses três parâmetros em termos de atendimento aos limites estabelecidos pela Resolução Conama 357/2005 - para rios Classe 2 - água doce, observou-se um salto de 2,5\% de atendimento no período $2011 / 2012$ para $50 \%$ de atendimento no período 2014/2015.
Apesar do parâmetro Coliformes Termotolerantes não atender em nenhum momento os limites estabelecidos pela Resolução Conama 357/2005, dos dez pontos analisados, em seis houve melhora na comparação de 2011 para 2015.

\subsection{Estudos correlativos}

\subsubsection{Maré e qualidade da água}

$\mathrm{Na}$ análise correlativa entre a altura das marés e o IQA, conforme apresentado na tabela 4, nota-se que há uma correlação negativa em todos os pontos $^{1}$. Ou seja, nos dias de maré mais baixa, o índice de qualidade da água tem se apresentado melhor, independentemente do sentido do fluxo (enchente ou vazante). Com relação à intensidade desta correlação, ela é moderada na maioria dos pontos, sendo desprezível em apenas uma ocasião.

\footnotetext{
${ }^{1}$ Este estudo não considerou nenhum modelo conceitual de circulação de água do Rio Cachoeira, apenas utilizou-se de informações existentes de maré para inferir algumas hipóteses quanto ao comportamento do fluxo do Rio em relação a alguns parâmetros de qualidade da água.
} 
Tabela 4 - Correlação entre maré e IQAA

\begin{tabular}{|c|c|c|c|}
\hline Ponto & $\begin{array}{c}\text { Coef. de } \\
\text { Pearson / } \\
\text { Spearman }\end{array}$ & Intensidade & $\begin{array}{c}\text { Situação da } \\
\text { maré }\end{array}$ \\
\hline RBC1 & $-0,48 /-0,52$ & Moderada & Enchente \\
\hline RBC3 & $-0,12 / 0,02$ & Desprezível & Enchente \\
\hline RBC4 & $-0,73 /-0,67$ & Mod. / Forte & Vazante \\
\hline RBC5 & $-0,62 /-0,65$ & Moderada & Enchente \\
\hline RBC6 & $-0,54 /-0,50$ & Moderada & Enchente \\
\hline RBC7 & $-0,65 /-0,68$ & Moderada & Enchente \\
\hline RBC8 & $-0,56 /-0,47$ & Moderada & Enchente \\
\hline RBC9 & $-0,68 /-0,66$ & Moderada & Vazante \\
\hline RBC10 & $-0,61 /-0,63$ & Moderada & Vazante \\
\hline RBC11 & $-0,42 /-0,34$ & Fraca & Enchente \\
\hline
\end{tabular}

Fonte: $O$ autor (2016)

Considerando apenas os parâmetros que representam quase $50 \%$ do peso do IQA (OD, DBO e Coliformes Termotolerantes), os resultados da correlação com a maré foram os seguintes:

Tabela 5 - Correlação entre maré e DBO, OD e CT

\begin{tabular}{|c|c|c|c|}
\hline \multirow{2}{*}{ Ponto } & \multicolumn{2}{|c|}{ Coef. de Pearson / Spearman } \\
\hline & DBO & OD & CT \\
\hline RBC1 & $0,45 / 0,32$ & $-0,54 /-0,51$ & $0,09 / 0,13$ \\
\hline RBC3 & $-0,29 /-0,13$ & $-0,40 /-0,47$ & $-0,16 / 0,13$ \\
\hline RBC4 & $0,80 / 0,71$ & $-0,77 /-0,74$ & $0,11 / 0,24$ \\
\hline RBC5 & $0,77 / 0,53$ & $-0,53 /-0,55$ & $0,45 / 0,59$ \\
\hline RBC6 & $0,72 / 0,60$ & $-0,44 /-0,31$ & $0,07 / 0,27$ \\
\hline RBC7 & $0,43 / 0,50$ & $-0,68 /-0,74$ & $-0,09 / 0,04$ \\
\hline RBC8 & $0,85 / 0,52$ & $-0,60 /-0,73$ & $0,37 / 0,17$ \\
\hline RBC9 & $0,38 / 0,37$ & $-0,62 /-0,54$ & $0,18 / 0,05$ \\
\hline RBC10 & $0,61 / 0,40$ & $-0,65 /-0,70$ & $-0,05 /-0,08$ \\
\hline RBC11 & $0,48 / 0,41$ & $-0,27 /-0,19$ & $-0,15 /-0,08$ \\
\hline
\end{tabular}

Fonte: $O$ autor (2016)

\subsection{Remoção de carga orgânica e estimativa de vazão}

Considerando os dados utilizados pela CAJ para dimensionamento dos projetos de esgoto ${ }^{2}$, estima-se que as novas Bacias 3, 4 e 5 ativadas até 2015, somadas, correspondem a uma contribuição de aproximadamente 5,8 toneladas de carga orgânica por dia. A fórmula utilizada levou em consideração uma eficiência de remoção de DBO de $80 \%$, calculada conforme a equação II:
Equação II - Remoção de DBO

$$
\mathrm{E}=\frac{\mathrm{C}_{\mathrm{e}}-\mathrm{C}_{\mathrm{s}}}{\mathrm{C}_{\mathrm{e}}} \times 100
$$

em que:

$E$ = eficiência de remoção (\%);

$\mathrm{Ce}=$ concentração na entrada;

Cs = concentração na saída;

Se considerarmos que todos os imóveis existentes nessas regiões da Bacia Hidrográfica do Rio Cachoeira possuíam o sistema de fossa e filtro com manutenção adequada (o que na prática não ocorria), ainda sim ter-se-ia uma contribuição aproximada $^{3}$ de 2,9 toneladas de carga orgânica sendo lançadas diretamente na bacia do rio $\mathrm{Ca}-$ choeira todos os dias.

Se calcularmos a contribuição per capita potencial de $\mathrm{DBO} / \mathrm{dia}^{4}$ e o volume potencial de esgoto/dia que têm sido deixados de ser lançado no Rio Cachoeira em função da ativação das novas economias de esgoto, chegaremos a valores parecidos. Estima-se que de 2011 a 2015 entre $2.300 \mathrm{Kg}$ e $4.645 \mathrm{Kg}$ de carga orgânica (DBO) deixaram de ser lançados diariamente no rio Cachoeira.

No que tange ao volume de esgoto que deixa de ser lançado no rio Cachoeira diariamente, estima-se que esse valor seja próximo de 5,7 milhões de litros/dia. Neste caso, considerou-se que $42 \%$ das ligações estavam regulares, conforme dados obtidos na $1^{\circ}$ fiscalização realizada pela Companhia Águas de Joinville em 2015 (Bacia 3).

Quanto aos níveis de vazão do Rio Cachoeira, monitoraram-se os mesmos no ponto CA1, localizado entre os pontos RBC1 e RBC3. Os dados são apresentados na Tabela 6 .

\footnotetext{
${ }^{2}$ Foi utilizado o valor de $385 \mathrm{mg} / \mathrm{L}$ para DBO de entrada na ETE Jarivatuba.

${ }^{3}$ A NBR 13969:97 considera uma eficiência teórica de 40 a 75\% de remoção de carga orgânica para sistemas fossa e filtro. Utilizou-se o valor de 50\% de eficiência para o cálculo.

${ }^{4}$ Foi considerado 54 gramas/usuário/dia para DBO e 160 litros/usuário/dia para esgoto, conforme referenciado pela literatura (PIVELI, 2001).
} 
Tabela 6 - Análise estatística descritiva de vazão - Ponto CA1

\begin{tabular}{|c|c|c|c|c|}
\hline Períodos e economias ativas & Média $\left(\mathbf{m}^{\mathbf{3}} \mathbf{s} \mathbf{s}\right)$ & Desvio Padrão $\left(\mathbf{m}^{\mathbf{3}} / \mathbf{s}\right)$ & Mínimo $\left(\mathbf{m}^{\mathbf{3}} \mathbf{s}\right)$ & Máximo $\left(\mathbf{m}^{3} / \mathbf{s}\right)$ \\
\hline $2010-2013-9.600$ economias ativas & 0,59 & 0,48 & 0,13 & 3,26 \\
\hline $2014-19.624$ economias ativas & 0,41 & 0,19 & 0,12 & 0,86 \\
\hline $2015-31.859$ economias ativas & 0,52 & 0,29 & 0,22 & 1,38 \\
\hline
\end{tabular}

Fonte: Adaptado de CAGNETI (2016)

A partir das vazões medidas, estimou-se pelas diferenças das mesmas o volume potencialmente reduzido entre os períodos de 2010 e 2015 . O volume médio calculado foi de 6.048 .000 litros/dia.

\section{DISCUSSÃO}

A média anual do IQA, considerando os 10 pontos analisados, passou de 27,53 em 2011 para 45,85 em 2015, saindo de uma classificação ruim para regular. De 2011 a 2013, o IQA variou pouco, influenciado pelo menor volume de ligações liberadas para uso e pela elevada quantidade de usuários não conectados ou conectados irregularmente à rede. A partir de 2014, quando a liberação de ligações se intensificou e deu-se início às fiscalizações nas áreas com cobertura de esgoto, o IQA apresentou a maior evolução.

Todos os dez pontos analisados apresentaram melhora. De forma geral, os pontos localizados nas áreas que receberam as primeiras obras de esgoto (bacias 3.1B, bacia 4 e 5 ) apresentaram as maiores evoluções no IQA. A explicação está no sentido das obras nascente-foz e na influência da maré, que é menor próximo da nascente.

Os parâmetros que apresentaram maior evolução no período analisado foram: Demanda Bioquímica de Oxigênio, Oxigênio Dissolvido, Coliformes Termotolerantes, Nitrogênio e Fósforo. Todos os pontos apresentaram variação positiva em seus parâmetros, porém, nem todos conseguiram atender aos limites estabelecidos pela Resolução Conama 357.
A matéria orgânica gerada nas novas bacias de esgoto ( 3,4 e 5) e não mais lançada no Rio $\mathrm{Ca}$ choeira, somada, corresponde a um volume entre 2,3 e 4,7 toneladas por dia. Já a contribuição de esgoto por pessoa foi estimada em 5,7 milhões de litros/dia. Os dois valores são compatíveis com a redução de vazão calculada entre os anos de 2010 e 2015, que foi de seis milhões de litros/dia, o que evidencia a redução no lançamento de esgoto neste trecho da Bacia Hidrográfica.

Existe relação entre o IQA e o nível da maré na Bacia Hidrográfica do Cachoeira. Quanto mais alta a maré, pior se apresenta o IQQA. Essa situação também ficou evidenciada na correlação dos parâmetros DBO e OD com o IQA. Quanto mais alta a maré, maior a $\mathrm{DBO}$ e menor a concentração de OD. A hipótese considerada é a de que o elevado grau de contaminação das águas do Rio Cachoeira, decorrente de décadas de lançamento de resíduos, aliado a um perfil de declividade pouco acentuado, possibilita que um grande volume de água poluída seja movimentado junto ao fluxo da maré. Assim, a poluição é levada até a Baia da Babitonga e depois trazida de volta para o centro e norte da cidade, num movimento que, infelizmente, dificultará a despoluição do rio.

Infelizmente ainda é grande o número de pessoas que não se ligam à rede de esgoto ou se ligam incorretamente no município de Joinville. Os prejuízos decorrentes dessa situação têm afetado diretamente o Rio Cachoeira e seus afluentes, assim como todo o sistema público de tratamento de esgoto. 


\section{CONCLUSÕES}

A compreensão das relações entre saneamento, saúde e meio ambiente constitui uma das etapas mais importantes no planejamento de qualquer política pública. Todo investimento requer um retorno, seja ele mensurável ou não. No caso do investimento em saneamento, especificamente no componente de esgotamento sanitário, o maior retorno reside na melhoria das condições ambientais, sociais e de saúde pública.

A partir deste estudo realizado na Bacia Hidrográfica do Rio Cachoeira, em Joinville, foi possível constatar que as obras de expansão do sistema de esgotamento sanitário realizadas no município vêm apresentando impacto positivo na qualidade da água dos rios que a compõem. Fato que ajuda a confirmar que os investimentos em esgotamento sanitário representam a principal solução para a despoluição de qualquer rio urbano.

Embora ainda falte bastante para a universalização do atendimento público de esgoto no município, já foi possível evidenciar diversos benefícios para a população. Dentre estes benefícios, destacam-se: a redução da exposição das pessoas aos agentes nocivos presentes no esgoto, redução do desconforto decorrente do mau cheiro antes frequente, mudança da paisagem da cidade (hoje já é possível ver pessoas pescando no rio) e, talvez o mais importante, o sentimento despertado de que o Rio Cachoeira pode se tornar novamente uma fonte de lazer e de ganhos econômicos para a sociedade joinvilense.

\section{REFERÊNCIAS}

BRASIL, Resolução CONAMA n³57, de 17 de março de 2005. Classificação de águas, doces, salobras e salinas do Território $\mathrm{Na}$ cional. Publicado no D.O.U.

CAGNETI, C. Análise da variação de parâmetros de qualidade de água na Bacia do Rio Cachoeira no período de 2010 a 2015. Trabalho de Conclusão de Curso (Graduaçãoem Engenharia Civil). Universidade do Estado de Santa Catarina. 2006.

CHEROBIM, A., P, M., S; MARTINS, G. A,; SILVEIRA, J. A. G., Abordagem metodológica qualitativo-quantitativa em pesquisas na área de administração. Disponível, em: http://www.anpad. org.br/diversos/trabalhos/EnANPAD/enanpad_2003/EPA/2003_ EPA249.pdf. Acesso em: 20/08/2016.

DERÍSIO, J. C. Introdução ao controle de poluição ambiental. 2. ed. São Paulo: Signus, 2000.

IBGE, Instituto Brasileiro de Geografia e Estatística. Pesquisa Nacional de Saneamento Básico 2008. Ministério do Planejamento, Orçamento e Gestão. Diretoria de Pesquisas. Coordenação de População e Indicadores Sociais. Rio de Janeiro, 2010.

IPPUJ - Fundação Instituto de Pesquisa e Planejamento para o Desenvolvimento Sustentável de Joinville. Joinville, cidade em dados 2015. Joinville, 2015.

MAIA, B. G. de O; KLOSTERMANN, D.; RIBEIRO, J. M. G.; SIMM, M.; OLIVEIRA, T. M. N.; BARROS, V. G. Bacias Hidrográficas da Região de Joinville. Gráfica e Editora 3 de Maio LTDA. Blumenau, Abril de 2014.

PIASENTIN, A.M.; SEMENSATTO JUNIOR, D.L.; SAAD, A.R.; MONTEIRO JUNIOR, A.J.; RACZKA, M.F. Índice de Qualidade da Água (IQA) do Reservatório Tanque Grande, Guarulhos (SP): Análise Sazonal e Efeitos do Uso e Ocupação do Solo. Geociências, São Paulo, v. 28, n. 3, p. 305-317, 2009.

PIVELI, R. P. Tratamento de esgotos sanitários. Apostila técnica. 2001. Disponível em: www.ctec.ufal.br/.../APOSTILA\%20-\%20 TRATAMENTO\%20DE... Acesso em: 15/06/2016. 